\title{
Chronic Duloxetine Treatment Induces Specific Changes in the Expression of BDNF Transcripts and in the Subcellular Localization of the Neurotrophin Protein
}

\author{
Francesca Calabrese', Raffaella Molteni' ${ }^{1,4}$, Paola F Maj ${ }^{1,4}$, Annamaria Cattaneo ${ }^{2,3}$, Massimo Gennarelli,3, \\ Giorgio Racagni ${ }^{1,2}$ and Marco A Riva*, \\ 'Department of Pharmacological Sciences, Center of Neuropharmacology, University of Milan, Milan, Italy; ${ }^{2}$ I.R.C.C.S. San Giovanni di \\ Dio-Fatebenefratelli, Brescia, Italy; ${ }^{3}$ Division of Biology and Genetic, Department of Biomedics and Biotechnologies Sciences, University \\ of Brescia, Brescia, Italy
}

\begin{abstract}
There is growing evidence that brain-derived neurotrophic factor (BDNF) can be relevant to mood disorders and that modulation of its biosynthesis following prolonged antidepressant treatment may contribute to neuroplastic changes required for clinical response. In the present study, we investigated the effects of the novel antidepressant duloxetine on BDNF in the rat brain. Duloxetine is a serotoninnorepinephrine reuptake inhibitor that differs from other antidepressants by virtue of its balanced potency on both neurotransmitter systems. We found that chronic, but not acute, treatment with duloxetine produces a robust increase of exon $V$ BDNF mRNA levels in frontal cortex when the animals were killed I or $24 \mathrm{~h}$ after the last administration. The expression of the neurotrophin was also increased in other cortical subregions, but not in the hippocampus. We also found that the increased expression of BDNF in frontal cortex was mainly sustained by enhanced mRNA levels for exons I and III, whereas the expression of exon IV was reduced. Protein analysis in different subcellular fractions showed that chronic treatment with duloxetine, but not with the prototypical SSRI fluoxetine, reduced mature BDNF in the cytosol, but markedly increased its levels in the crude synaptosomal fraction. Our data suggest that chronic treatment with the novel antidepressant duloxetine not only produces a marked upregulation of BDNF mRNA and protein, but may also affect the subcellular redistribution of the neurotrophin. These changes might improve synaptic plasticity and cognitive function that are defective in depressed subjects.
\end{abstract}

Neuropsychopharmacology (2007) 32, 235 I-2359; doi:I 0. I 038/sj.npp. I 30I360; published online 28 February 2007

Keywords: neurotrophin; antidepressant; fluoxetine; frontal cortex; synaptic plasticity

\section{INTRODUCTION}

Based on the observation that antidepressant drugs increase synaptic levels of monoamines, primarily serotonin and norepinephrine, it has been postulated that depression is associated with decreased synaptic concentration of such monoamine (Leonard, 2001). However, the time delay for the therapeutic action of antidepressants has led to hypothesize that clinical responses are achieved through neuroadaptive mechanisms, which involve an array of events including changes in signal transduction, modulation of gene expression, and stimulation of neurogenesis (Santarelli et al, 2003; Castren, 2005; Berton and Nestler,

\footnotetext{
*Correspondence: Professor MA Riva, Department of Pharmacological Sciences, Center of Neuropharmacology, University of Milan, Via Balzaretti 9, 20133 Milan, Italy, Tel: + 3902503 |8334, Fax: + 39 02503 | 8278, E-mail: M.Riva@unimi.it

${ }^{4}$ These authors contributed equally to this work.

Received 25 July 2006; revised 10 January 2007; accepted 15 January 2007
}

2006; Duman and Monteggia, 2006). In this regard, one of the most extensively investigated targets is brain-derived neurotrophic factor (BDNF), a member of the neurotrophin family playing a crucial role in cellular plasticity and neuronal remodeling (Poo, 2001; Nagappan and Lu, 2005). Indeed a 'neurotrophic hypothesis' of depression has been developed based on an array of clinical and preclinical data. BDNF mRNA levels are reduced in the brains of suicide victims (with the possible diagnosis of depression) (Chen et al, 2001) and are also decreased by stress, an important precipitating factor in mood disorders. Moreover, chronic antidepressant treatment can increase BDNF expression, thus counteracting the effects of stress (Nibuya et al, 1995; Tsankova et al, 2006; Tardito et al, 2006), whereas mice with impaired synthesis of the neurotrophin fail to respond to antidepressant drugs (Saarelainen et al, 2003; Monteggia et al, 2004).

On this basis, the upregulation of BDNF appears to contribute to neuroadaptive changes, which might support the efficacy of pharmacological treatment in individuals who show clinical response. 
However, a close examination of the literature indicates that, apart from the strong modulation of BDNF by electroconvulsive therapy, limited changes (in terms of magnitude and anatomical profile) have been described with other antidepressants (Tardito et al, 2006). Moreover, restricted information is present on the modulation of neurotrophin protein levels, which rarely parallel the changes observed at mRNA levels (Tardito et al, 2006). In our study we have investigated the effects produced by chronic administration of the new antidepressant drug duloxetine, a potent and balanced serotonin and norepinephrine reuptake inhibitor (Bymaster et al, 2005), on the expression of the neurotrophin BDNF. We carried out a detailed temporal and anatomical analysis of the transcription of the coding exon V mRNA as well as of its $5^{\prime}$ exons. Moreover, in order to evaluate the possibility that antidepressant treatment may regulate processing and sorting of BDNF protein, we investigated the modulation of precursor and mature BDNF proteins in different subcellular compartments, where the neurotrophin may subserve specific cellular functions.

\section{MATERIALS AND METHODS}

\section{Materials}

General reagents were purchased from Sigma-Aldrich (Milan, Italy), and molecular biology reagents were obtained from Ambion (Austin, TX, USA), New England Biolabs (Beverly, MA, USA), Promega (Milan, Italy), and Bioline (London, UK). Duloxetine was obtained from Eli Lilly (Sesto Fiorentino, Italy).

\section{Animals and Pharmacological Treatments}

Male Sprague-Dawley rats (Charles River, Calco, Italy) weighing 225-250 g were used throughout the experiments. Rats were housed for 2 weeks before any treatment and maintained under a 12-h light/12-h dark cycle with food and water available ad libitum. The following experimental groups were used: vehicle, animals treated for 21 days with vehicle solution; acute duloxetine, animals received the vehicle for 20 days and a single administration of duloxetine, $10 \mathrm{mg} / \mathrm{kg}$, on the $21 \mathrm{st}$ day, and were killed 1 or $24 \mathrm{~h}$ later; chronic duloxetine, animals received daily administration of duloxetine, $10 \mathrm{mg} / \mathrm{kg}$, for 3 weeks and were killed 1 or $24 \mathrm{~h}$ after the last administration of the drug; chronic fluoxetine, animals received daily administration of fluoxetine, $10 \mathrm{mg} / \mathrm{kg}$, for 3 weeks and were killed $24 \mathrm{~h}$ after the last administration of the drug. Vehicle, duloxetine, and fluoxetine were administered by gavage. Animals were killed by decapitation and the brain regions of interest were rapidly dissected. Hippocampus, entorhinal cortex, and hypothalamus were dissected from the whole brain, whereas prefrontal cortex (defined as $\mathrm{Cg} 1, \mathrm{Cg} 3$, and IL subregions corresponding to the plates 6-10 according to the atlas of Paxinos and Watson), frontal cortex (comprising regions Fr1-3, from the same slice as prefrontal cortex), and parietal cortex (Par1-Par2 from plates 10 to 17) were dissected from 2-mm-thick slices (Paxinos and Watson, 1996). The brain specimens were frozen on dry ice and stored at $-80^{\circ} \mathrm{C}$ for further analysis.
All animal handling and experimental procedures were performed in accordance with the EC guidelines (EEC Council Directive 86/609 1987) and the Italian legislation on animal experimentation (Decreto Legislativo 116/92).

\section{RNA Preparation}

Tissue from different brain structures was homogenized in $4 \mathrm{M}$ guanidinium isothiocyanate (containing $25 \mathrm{mM}$ sodium citrate, pH 7.5, 0.5\% sarcosyl, and 0.1\% 2-mercaptoethanol). Total RNA was isolated by phenol/chloroform extraction and quantification was carried out by spectrophotometric analysis.

\section{RNase Protection Assay}

A transcription kit (MAXI script; Ambion) was used to generate cRNA probes and ${ }^{32} \mathrm{P}$-CTP was utilized as a radiolabeled nucleotide. The cRNA probes and the relative protected fragments (pf) were as follows: $\mathrm{BDNF}=800 \mathrm{bp}, \mathrm{pf}=740 \mathrm{bp}$; $\beta$-actin (pTRI- $\beta$-actin-rat, Ambion) $=164 \mathrm{bp}, \mathrm{pf}=126 \mathrm{bp}$. The cRNA probe of BDNF was complementary to exon $\mathrm{V}$, which is common to all neurotrophin transcripts (Timmusk et al, 1993).

The RNase protection assay was carried out on a $10-\mu \mathrm{g}$ sample of total RNA as described previously (Riva et al, 1996). Briefly, after ethanol precipitation, total RNA was dissolved in $20 \mu \mathrm{l}$ of hybridization solution (80\% formamide, $40 \mathrm{mM}$ PIPES, $\mathrm{pH} 6.4,400 \mathrm{mM}$ sodium acetate, $\mathrm{pH}$ 6.4 , and $1 \mathrm{mM}$ EDTA) containing $150000 \mathrm{cpm}$ of ${ }^{32} \mathrm{P}$-labeled BDNF cRNA probe (specific activity $>10^{8} \mathrm{cpm} / \mu \mathrm{g}$ ) and $50000 \mathrm{cpm}$ of ${ }^{32} \mathrm{P}$-labeled $\beta$-actin probe. After being heated at $85^{\circ} \mathrm{C}$ for $10 \mathrm{~min}$, the cRNA probes were allowed to hybridize to the endogenous RNAs at $45^{\circ} \mathrm{C}$ overnight.

At the end of hybridization, the solution was diluted with $200 \mu \mathrm{l}$ of RNase digestion buffer $(300 \mathrm{mM} \mathrm{NaCl}, 10 \mathrm{mM}$ Tris $\mathrm{HCl}, \mathrm{pH} 7.4$, and $5 \mathrm{mM}$ EDTA, $\mathrm{pH}$ 7.4) containing a 1:400 dilution of a RNase cocktail $(1 \mathrm{mg} / \mathrm{ml}$ RNase A and $20 \mathrm{U} / \mathrm{ml}$ RNase T1) and incubated for $30 \mathrm{~min}$ at $30^{\circ} \mathrm{C}$. Proteinase $\mathrm{K}$ $(10 \mu \mathrm{g})$ and sodium dodecyl sulfate (SDS; $10 \mu \mathrm{l}$ of $20 \%$ stock solution) were then added to the sample and the mixture was incubated at $37^{\circ} \mathrm{C}$ for an additional $15 \mathrm{~min}$. At the end of incubation, the sample was extracted with phenol/ chloroform and ethanol-precipitated. The pellet containing the RNA:RNA hybrids was dried and resuspended in loading buffer ( $80 \%$ formamide, $0.1 \%$ xylene cyanol, $0.1 \%$ bromophenol blue, and $2 \mathrm{mM}$ EDTA), boiled at $95^{\circ} \mathrm{C}$ for $5 \mathrm{~min}$, and separated on $5 \%$ polyacrylamide gel under denaturing conditions ( $7 \mathrm{M}$ urea). The protected fragments were visualized by autoradiography.

\section{RT-PCR and Analysis of BDNF Isoforms Expression}

The analysis of four $5^{\prime}$ exons (exon I, II b/c, III, IV) was carried out by RT-PCR. Reverse transcription was carried out using a mix of Superscript II Reverse T enzyme and Taq DNA polymerase enzyme provided by Invitrogen. Two micrograms of total RNA from frontal cortex was mixed with $1 \mu \mathrm{l}$ of $0.5 \mu \mathrm{g} /$ $\mu \mathrm{l}$ random hexamer (Promega), $10 \mu \mathrm{l}$ of $5 \times$ buffer (Invitrogen), $1 \mu \mathrm{l}$ of $20 \mathrm{mM}$ dNTPs, $1 \mu \mathrm{l}$ of $20 \mathrm{mM}$ DTT (Invitrogen), $0.4 \mu \mathrm{l}$ of $40 \mathrm{U} / \mu \mathrm{l}$ RnaseOUT (Invitrogen), and $2 \mu \mathrm{l}$ Superscript II/Taq mix in a final volume of $50 \mu \mathrm{l}$. The reaction mix was incubated at $42^{\circ} \mathrm{C}$ for $55 \mathrm{~min}$ and $70^{\circ} \mathrm{C}$ for $15 \mathrm{~min}$, and then the enzyme was inactivated at $95^{\circ}$ for $10 \mathrm{~min}$. 
To perform the PCRs, $3 \mu \mathrm{l}$ of RT product was mixed with $2.5 \mu \mathrm{l} 10 \times$ buffer (Bioline), $0.3-0.5 \mu \mathrm{l}$ of $1.5 \mathrm{mM} \mathrm{MgCl}_{2}, 2.5 \mu \mathrm{l}$ of $2 \mathrm{mM} \mathrm{dNTP}, 0.3-0.8 \mu \mathrm{l}$ of each forward and reverse primer, and $1.25 \mathrm{U}$ of Taq polymerase in a final volume of $25 \mu \mathrm{l}$.

Different sets of primer pairs were used in the same reaction tube to co-amplify the target gene, together with primers for $\beta$-actin.

Standard PCR cycle conditions were as follows: one denaturation step for $2 \mathrm{~min}$ at $95^{\circ} \mathrm{C}$, followed by $25-35$ cycles with $30 \mathrm{~s}$ of denaturation at $95^{\circ} \mathrm{C}, 20 \mathrm{~s}$ of primer annealing at $58-60^{\circ} \mathrm{C}$, and $30 \mathrm{~s}-1 \mathrm{~min}$ of elongation at $72^{\circ} \mathrm{C}$, followed by a final extension of $1 \mathrm{~min}$. The number of cycles and primer concentrations was chosen experimentally in order to fall into the exponential phases of the amplification reaction. With the co-amplification procedure it is possible to compare the expression of each BDNF transcript and to overcome the inherent variation present within any individual PCR by normalizing to the $\beta$-actin mRNA level. RNA template and mock controls run in parallel to PCRs never gave amplification products. The following forward and reverse primers were used: BDNF exon I-forward: GAC AGT CAT TGG TAA CCT CGC, reverse: GTA GGC CAA GTT GCC TTG TCC GT (461 bp, $\left.T_{\mathrm{m}}: 57^{\circ} \mathrm{C}\right)$; BDNF exon II-forward: CTG TGT CGC CCT TAA AAA GC, reverse: GTA GGC CAA GTT GCC TTG TCC GT (300$380 \mathrm{bp}, T_{\mathrm{m}}: 58^{\circ} \mathrm{C}$ ); BDNF exon III - forward: GAG TAT TAC CTC CGC CAT GCA A, reverse: GTA GGC CAA GTT GCC TTG TCC GT (334 bp, $T_{\mathrm{m}}: 58^{\circ} \mathrm{C}$ ); BDNF exon IV-forward: GGC TTT GAT GAG ACC GGG TTC CCT, reverse: GTA GGC CAA GTT GCC TTG TCC GT (276bp, $\left.T_{\mathrm{m}}: 57^{\circ} \mathrm{C}\right)$; and $\beta$-actin-forward: GGG AAA TCG TGC GTG ACA TT, reverse: CGG ATG TCA ACG TCA CAC TT (252 bp, $T_{\mathrm{m}}$ : 57/ $58^{\circ} \mathrm{C}$ ). We used the Agilent 2100 bioanalyzer for semiquantitative RT-PCR analysis of BDNF isoforms (Barbon et al, 2003). The bioanalyzer uses lab-on-a-chip technology to perform gel electrophoresis. Samples are separated electrophoretically in a polymer solution, much as in capillary electrophoresis. The instrument detects laserinduced fluorescence using an intercalating dye, which is added to the polymer. The bioanalyzer software automatically calculates the size and concentration of each separate band and displays the result in real time, generating a gellike image. The PCR products were analyzed using DNA 500 Lab kit chips (Agilent Technologies, Waldbronn, Germany). All chips were prepared according to the manufacturer's instructions. In brief, the gel matrix was prepared by adding $25 \mu \mathrm{l}$ of dye to a gel vial. The gel-dye mixture was passed through a spin filter. Each chip was filled with $9 \mu \mathrm{l}$ of the gel-dye mixture. Samples and ladder wells were filled with $5 \mu \mathrm{l}$ of DNA marker solution before the addition of $1 \mu \mathrm{l}$ of ladder and samples (total 50-500 ng) in the respective wells. The chips were vortexed and placed in the bioanalyzer. The ratio of the concentration of each amplified product to that of the co-amplified housekeeping gene allowed a relative estimate of the mRNA levels (Barbon et al, 2003).

\section{Preparation of Protein Extract and Western Blot Analysis}

Tissues were homogenized in a glass-glass potter in cold $0.32 \mathrm{M}$ sucrose solution containing $1 \mathrm{mM}$ HEPES, $0.1 \mathrm{mM}$ EGTA, and $0.1 \mathrm{mM}$ phenylmethylsulfonyl fluoride, $\mathrm{pH} 7.4$, in the presence of a complete set of protease inhibitors and a phosphatase inhibitor cocktail. The homogenized tissue was centrifuged at $1000 \mathrm{~g}$ for $10 \mathrm{~min}$ to obtain a pellet (P1), corresponding to the nuclear fraction; the supernatant (S1) was centrifuged at $9000 \mathrm{~g}$ for $15 \mathrm{~min}$ to obtain a clarified fraction of cytosolic proteins (S2) and the pellet (P2), corresponding to the crude synaptosomal membranes, which was resuspended in a buffer (20 mM HEPES, $0.1 \mathrm{mM}$ DTT, $0.1 \mathrm{mM}$ EGTA) with protease and phosphatase inhibitors.

In the present study, Western blot analysis was performed to investigate the levels of precursor (pro) and mature (m) BDNF protein in S2 and P2 fractions. After adjusting total protein concentrations to the same amount $(10 \mu \mathrm{g})$, all samples were run on a SDS-14\% polyacrylamide gel under reducing conditions, and proteins were then electrophoretically transferred onto PVDF membranes (Amersham). Blots were blocked with $10 \%$ nonfat dry milk and then incubated with primary anti-BDNF polyclonal antibody (1:1000, $4^{\circ} \mathrm{C}$, overnight; Santa Cruz Biotechnology, Santa Cruz, CA). Membranes were then incubated for $1 \mathrm{~h}$ at room temperature with a 1:5000 dilution of peroxidase-conjugated anti-rabbit IgG (Cell Signaling) and BDNF immunocomplexes were visualized by chemiluminescence using the ECL Western Blotting kit (Amersham Life Science, Milan, Italy) according to the manufacturer's instructions. BDNF precursor and mature forms were detected by evaluating the band density at 32 and $14 \mathrm{kDa}$, respectively.

Results were standardized to $\beta$-actin, as control protein, which was detected by evaluating the band density at $43 \mathrm{kDa}$ after the membranes were probed with a polyclonal antibody (1:10000 dilution, Sigma) followed by a 1:10000 dilution of peroxidase-conjugated anti-mouse IgG (Sigma).

\section{Densitometric and Statistical Analyses}

The levels of mRNA and protein for BDNF and $\beta$-actin were calculated by measuring the optical density of the autoradiographic bands using Quantity One software (Bio$\mathrm{Rad})$. To ensure that autoradiographic bands were in the linear range of intensity, different exposure times were used. $\beta$-actin was employed as internal standard for the RNase protection assay and Western blotting because its expression was not regulated by acute or chronic antidepressant treatment. Statistical comparisons were carried out using Student's $t$-test (unpaired two-tail) or one-way analysis of variance (ANOVA) followed by Fisher's protected least significant difference. Significance for all tests was assumed to be at least $p<0.05$.

Data are presented as means \pm standard error (SEM), with each individual group comprising 6-8 samples. For graphic clarity, optical densities from experimental groups were expressed and presented as a mean percentage of the control group, namely, the group that received only the vehicle.

\section{RESULTS}

The major aim of this study was to carry out a detailed analysis of BDNF mRNA and protein levels following duloxetine treatment. As illustrated in Figure 1a, chronic 
duloxetine treatment produced a significant increase of BDNF exon $\mathrm{V}$ mRNA levels in frontal cortex. In fact, the animals killed $1 \mathrm{~h}$ after the end of the treatment show a significant upregulation of BDNF mRNA levels $(+179 \%$, $p<0.001$ ), an effect that was also found when the rats were killed $24 \mathrm{~h}$ after the last drug administration $(+104 \%$, $p<0.01$ ). Moreover, single-comparison analysis indicated that BDNF mRNA levels in animals chronically treated with duloxetine and killed $1 \mathrm{~h}$ after the last administration of the antidepressant were significantly higher than in those killed at $24 \mathrm{~h}(+75 \%, p<0.05)$. Despite the evidence that several antidepressant drugs upregulate the expression of BDNF in

a
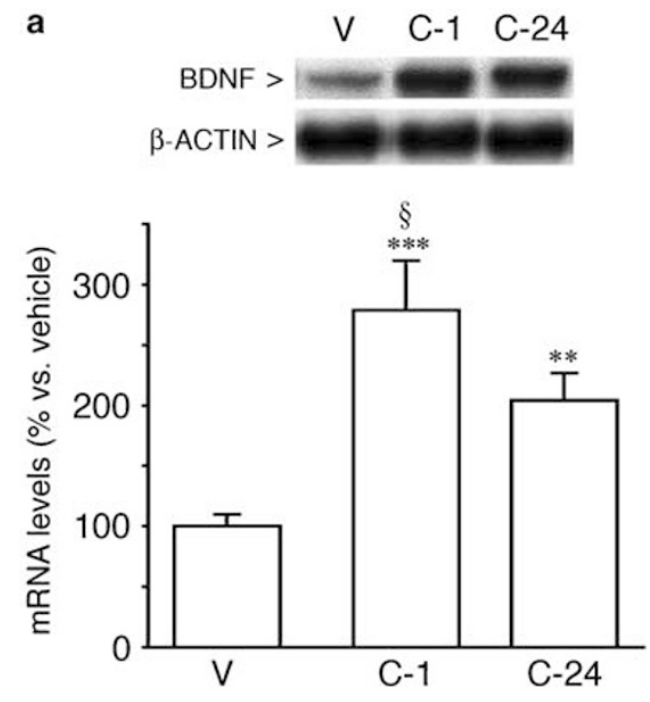

b
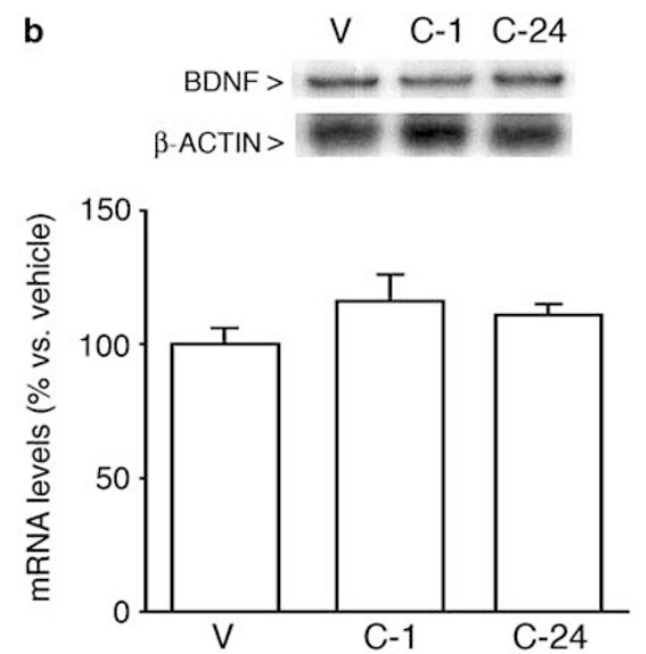

Figure I Effect of chronic treatment (2I days) with duloxetine (I $0 \mathrm{mg} /$ $\mathrm{kg}$ ) on BDNF exon $\mathrm{V}$ mRNA levels in rat frontal cortex and hippocampus. Animals received $2 \mathrm{I}$ daily injections of duloxetine and were killed I (C-I) or 24 (C-24) $h$ after the last drug administration. Analysis of BDNF exon $V$ mRNA levels was performed in frontal cortex (a) and hippocampus (b). The top of each panel shows a representative picture of the RNase protection assay, with arrows indicating the protected fragments for BDNF or $\beta$-actin, used as internal standard. The quantitative data of BDNF mRNA levels, presented in the lower part of each panel, are expressed as a percentage of control values (animals treated with vehicle, set at I00\%). Bar graphs show means \pm SEM from eight independent determinations. *** $p<0.01$ and $* * * * 00.001$ vs vehicle and ${ }^{\S} p<0.05$ vs C-24 (one-way ANOVA with Fisher's PLSD). rat hippocampus following repeated injection (Tardito et al, 2006), our results fail to demonstrate any significant change of neurotrophin exon $\mathrm{V}$ mRNA levels $\left(\mathrm{F}_{3,36}=1.128\right.$, $p=0.353)$ after chronic treatment with duloxetine in this brain region (Figure 1b). The changes in BDNF expression observed in frontal cortex appear to result from repetitive drug injection. In fact, 1 or $24 \mathrm{~h}$ after a single administration of the antidepressant, no significant changes were observed on BDNF mRNA levels in frontal cortex as well as in the hippocampus (Table 1). Moreover, no significant differences were observed after a short-term ( 7 day) duloxetine treatment (data not shown).

To extend the analysis of the effects produced by duloxetine administration on BDNF expression, we analyzed exon $\mathrm{V}$ mRNA levels in other brain regions (Table 2). The acute injection of duloxetine did not produce any significant change in neurotrophin mRNA levels, with the exception of the prefrontal cortex $(+40 \%, p<0.05)$. Following chronic drug administration, when the rats were killed $1 \mathrm{~h}$ after the last dose of duloxetine, significantly increased levels of BDNF exon $\mathrm{V}$ mRNA were found in several brain structures including prefrontal cortex $(+28 \%$, $p<0.05)$, entorhinal cortex $(+60 \%, p<0.01)$, and parietal cortex $(+25 \%, p<0.01)$, but not in the hypothalamus $\left(\mathrm{F}_{3,25}=2.089, p=0.132\right)$. When measured $24 \mathrm{~h}$ later, the

Table I Effect of Acute Treatment with Duloxetine $(10 \mathrm{mg} / \mathrm{kg})$ on BDNF mRNA Levels in Rat Frontal Cortex and Hippocampus

\begin{tabular}{lccccc}
\hline & \multicolumn{2}{c}{$\mathbf{I ~ h}$} & & \multicolumn{2}{c}{$\mathbf{2 4 h}$} \\
\cline { 2 - 3 } \cline { 5 - 6 } Brain region & Vehicle & DLX & & Vehicle & DLX \\
\hline Frontal cortex & $100 \pm 8$ & $79 \pm 29$ & & $100 \pm 7$ & $97 \pm 11$ \\
Hippocampus & $100 \pm 6$ & $106 \pm 7$ & & $100 \pm 5$ & $112 \pm 6$ \\
\hline
\end{tabular}

Rats received a single bolus of duloxetine $(D L X)$ and were killed I or $24 \mathrm{~h}$ later. The data, expressed as percentage of control values (animals treated with vehicle, 100\%), represent the mRNA levels for BDNF exon $V$ and are means \pm SEM from six to eight independent determinations.

Table 2 Effect of Acute and Chronic Treatment (2I days) with Duloxetine $(10 \mathrm{mg} / \mathrm{kg})$ on BDNF mRNA Levels in Different Rat Brain Regions

\begin{tabular}{|c|c|c|c|c|}
\hline Area & Vehicle & $\begin{array}{c}\text { Acute } \\
\text { I h }\end{array}$ & $\begin{array}{c}\text { Duloxetine } \\
\text { I h }\end{array}$ & $\begin{array}{c}\text { Duloxetine } \\
24 \mathrm{~h}\end{array}$ \\
\hline Prefrontal cortex & $100 \pm 8$ & $140 \pm 8 *$ & $128 \pm 10 *$ & $136 \pm 15 *$ \\
\hline Entorhinal cortex & $100 \pm 12$ & $99 \pm 14$ & $160 \pm 13^{* * *}$ & $89 \pm 12$ \\
\hline Parietal cortex & $100 \pm 4$ & $118 \pm 4$ & $125 \pm 8 * * *$ & $99 \pm 7$ \\
\hline Hypothalamus & $100 \pm 9$ & $139 \pm 28$ & $82 \pm 12$ & $107 \pm 15$ \\
\hline
\end{tabular}

The data represent the mRNA levels for BDNF exon $\mathrm{V}$, expressed as a percentage of control values (animals treated with vehicle, 100\%). Values are means \pm SEM from eight independent determinations for the following experimental groups: vehicle; acute I h, acute treatment/kill at I h posttreatment; duloxetine I h, chronic treatment/kill at I h post-treatment; duloxetine $24 \mathrm{~h}$, chronic treatment/kill at $24 \mathrm{~h}$ post-treatment. $* \mathrm{p}<0.05$ and *** $p<0.01$ vs vehicle (one-way ANOVA with Fisher's PLSD). 
mRNA levels for the neurotrophin were still significantly increased only in prefrontal cortex $(+36 \%, p<0.05)$.

The rat BDNF gene has a complex organization because different $5^{\prime}$ exons, which are under the control of separate promoters, can be alternatively spliced to the common exon $\mathrm{V}$, coding for the BDNF protein (Timmusk et al, 1993; Liu et al, 2006). Hence, in order to gain further insight into BDNF modulation in frontal cortex, we used RT-PCR to investigate the expression of such $5^{\prime}$ exons. As summarized in Figure 2, duloxetine treatment modulated significantly the expression of isoforms $1,2 c, 3$, and 4 , but not that of isoform $2 \mathrm{~b}\left(\mathrm{~F}_{3,28}=1.670, p=0.2\right)$. We found that rats treated for 21 days with duloxetine and killed $1 \mathrm{~h}$ after the last injection showed a significant increase in mRNA levels for exons I, IIc, and III $(+67 \%, p<0.001 ;+27 \%, p<0.05$; $+29 \%, p<0.001$, respectively), whereas the expression of exon IV was reduced $(-19 \%, p<0.001)$. Instead, when measured $24 \mathrm{~h}$ later, duloxetine significantly increased the expression of exon I $(+24 \%, p<0.05)$, while decreasing the mRNA levels for exon IV $(-29 \%, p<0.001)$. As previously observed for the common BDNF exon $\mathrm{V}$, no changes were observed in mRNA levels for the different exons $1 \mathrm{~h}$ after acute duloxetine treatment (Figure 2).

To understand whether the regulation of BDNF mRNA after prolonged duloxetine administration was paralleled by changes in protein levels, we performed Western blot analysis on two different subcellular fractions obtained by subsequent centrifugation steps: the cytosolic fraction (S2) and the crude synaptosomal fraction (P2). We found that in frontal cortex the mature form of BDNF (mBDNF) was markedly increased in the P2 fraction $(+261 \%, p<0.001)$ of rats chronically treated with duloxetine and killed $24 \mathrm{~h}$ after the last administration (Figure 3a and b), whereas the levels
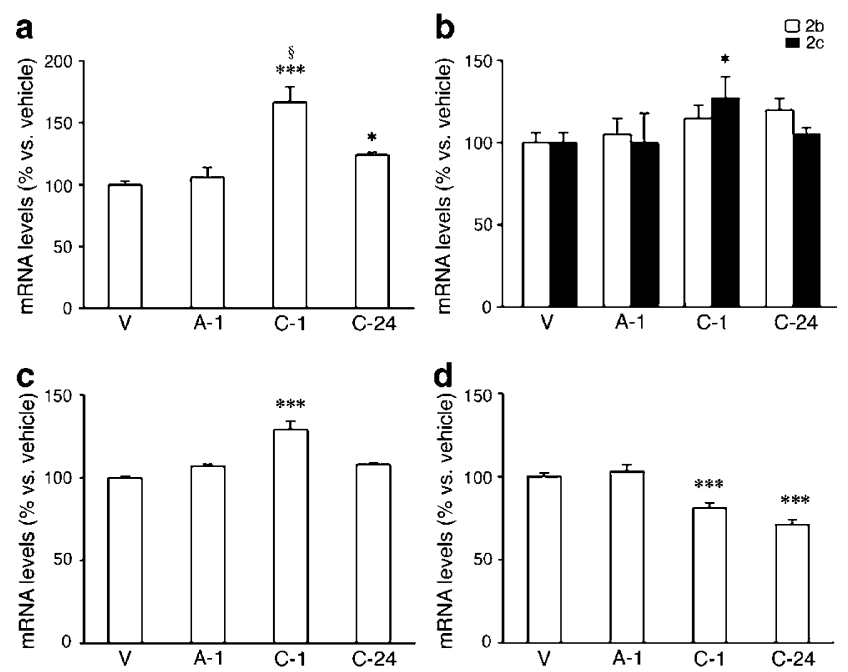

Figure 2 Effect of acute or chronic treatment (2I days) with duloxetine $(10 \mathrm{mg} / \mathrm{kg})$ on the expression of different $5^{\prime}$ BDNF exons in rat frontal cortex. The data represent the mRNA levels for exon I (a), exon II b/c (b), exon III (c), and exon IV (d) expressed as a percentage of control values (animals treated with vehicle, 100\%). Bar graphs show means \pm SEM from seven independent determinations for the following experimental groups: $\mathrm{V}$, vehicle; A-I, acute treatment/kill at I h post-treatment; C-I, chronic treatment/kill at I h post-treatment; C-24, chronic treatment/kill at $24 \mathrm{~h}$ post-treatment. $* p<0.05$ and $* * * * 00.00$ I vs vehicle and ${ }^{{ }} p<0.00$ I vs C-24 (one-way ANOVA with Fisher's PLSD). of its precursor form (proBDNF) were not altered. Conversely, in the cytosolic compartment (Figure 3a and c), chronic duloxetine treatment reduced the levels of mBDNF $(-44 \% ; p<0.05)$ as well as of proBDNF $(-28 \%$, $p<0.05)$. In line with mRNA data, no significant changes in mature or proBDNF levels were observed in S2 or P2 prepared from the hippocampus of rats chronically treated with duloxetine (Figure 3d-f).

Although previous reports have investigated the effect of selective serotonin reuptake inhibitor (SSRI) on BDNF mRNA levels, no data are available on the possible modulation of its protein in specific subcellular compartments. Hence, in order to compare the effects brought about by prolonged duloxetine treatment with those produced by a SSRI, we have measured the levels of mBDNF and proBDNF in subcellular fractions from hippocampus and frontal cortex after chronic treatment with fluoxetine, a prototypical SSRI antidepressant. The results of these experiments fail to show a significant modulation of BDNF (mature and precursor) levels in the crude synaptosomal fraction as well as in the cytosolic compartment from frontal cortex (Figure $4 \mathrm{a}-\mathrm{c}$ ) and hippocampus (Figure $4 \mathrm{~d}-\mathrm{f}$ ).

\section{DISCUSSION}

Our study demonstrates that chronic treatment with the novel antidepressant duloxetine elicits a marked increase of mRNA expression for BDNF exon $\mathrm{V}$ in rat frontal cortex, an effect that is sustained by the enhanced transcription of specific $5^{\prime}$ BDNF exons. Moreover, we provide evidence that transcriptional changes are paralleled by a significant increase of BDNF protein in the crude synaptosomal fraction, suggesting that chronic antidepressant treatment may also modulate the subcellular distribution of the neurotrophin.

One peculiarity of our results is that duloxetine, which differs from other antidepressants by virtue of its balanced potency on noradrenergic and serotonergic systems (Bymaster et al, 2005), is able to modulate BDNF in different cortical regions, primarily at the level of frontal cortex. Although differences in the experimental paradigms make it difficult to establish a direct comparison between these results and those found in the literature, our data suggest that a balanced inhibitory activity on 5-HT and NE membrane transporters may generate a more robust upregulation of BDNF expression in cortical regions when compared with drugs with different mechanisms of action (Nibuya et al, 1995; Tardito et al, 2006). Since most antidepressants appear to affect hippocampal BDNF mRNA levels in the dentate gyrus, the lack of duloxetine effect in this brain region might be due to the fact that our analysis was conducted on whole hippocampus, which may limit the detection of small changes in selected subfields (CA1, CA3, DG) where such modifications can be localized (De Foubert et al, 2004; Molteni et al, 2006).

Although it is difficult to establish whether the strong increase of BDNF expression in frontal cortex can be ascribed to the dual mechanism that characterizes duloxetine, major changes at this level have been reported after electroconvulsive treatment or after chronic treatment with drugs that act on different (more than a single) neuro- 
a

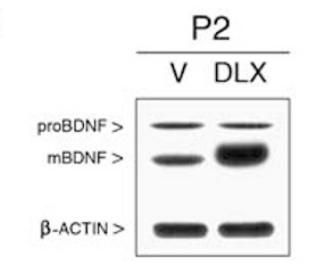

b
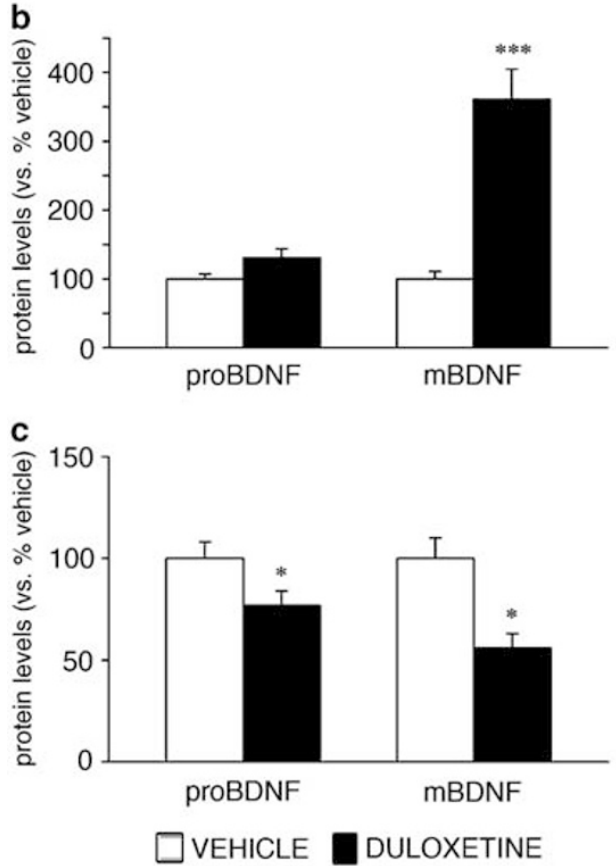

d
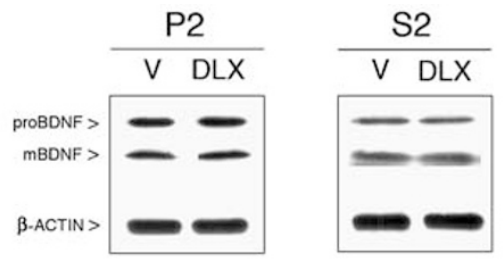

e

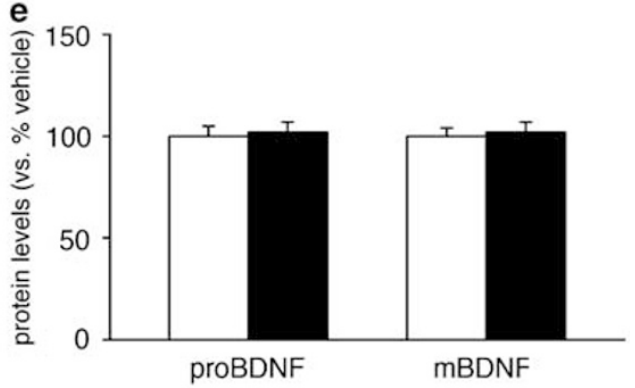

f

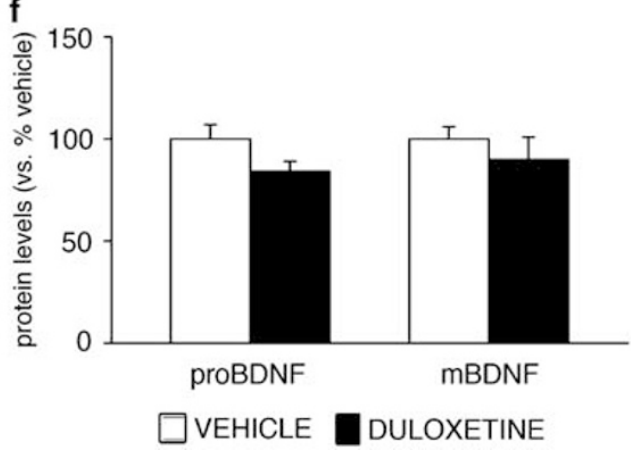

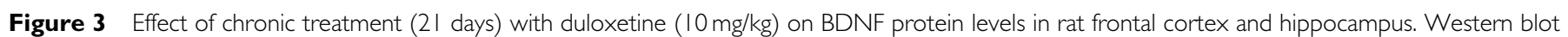
analysis of BDNF protein levels was carried out in P2 and S2 fractions of frontal cortex (a) and hippocampus (d) from rats chronically treated with vehicle (V) or duloxetine (DLX) and killed $24 \mathrm{~h}$ after the last drug administration. Arrows indicate the precursor (proBDNF) and the mature (mBDNF) forms of BDNF

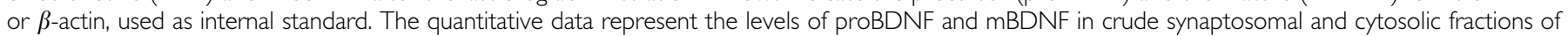
frontal cortex ( $b$ and c, respectively) or hippocampus (e and f, respectively) and are expressed as a percentage of control values (animals treated with vehicle, set at 100\%). Bar graphs show means \pm SEM from seven or eight independent determinations. $* p<0.05$ and $* * * p<0.00$ I vs vehicle (Student's t-test, unpaired two tail).

transmitter systems (Tardito et al, 2006). Both 5-HT and NE systems innervate frontal cortex, a brain region that is characterized by reduced metabolic activation and morphological changes in major depression (Drevets et al, 1997; Rajkowska et al, 1999; Fossati et al, 2004). Extensive data support a reciprocal modulation between 5-HT and NE, although a major emphasis has been placed on their interaction at the synaptic level (Lindvall et al, 1978). As chronic antidepressant treatment produces neuroadaptive changes at the intracellular level that may lead to modifications in gene transcription (Tardito et al, 2006), we hypothesize that the combined and balanced activity on 5-HT and NE systems might synergize intracellularly to upregulate BDNF expression in the long-term.

Similar to other antidepressants (Nibuya et al, 1995), duloxetine modulates BDNF expression only after chronic treatment, but not in response to a single administration or a short-term paradigm (7 days, data not show), providing further support to the notion that neurotrophin modulation represents an adaptive mechanism to repeated antidepressant treatment.

The data emerging from our chronic experiments indicate that duloxetine produces a stable increase of BDNF mRNA levels, the effect being evident 1 or $24 \mathrm{~h}$ after the last administration. The statistically significant increase of BDNF mRNA levels observed at $1 \mathrm{~h}$, with respect to $24 \mathrm{~h}$, suggests that the single injection of duloxetine in chronically treated rats induced neurotrophin transcription, but it does not produce the same effect in animals that have been administered with vehicle for 20 days. It is therefore possible to hypothesize that prolonged treatment with the antidepressant duloxetine may stably enhance BDNF expression but it could also 'sensitize' the activity of neurotransmitters or intracellular pathways that regulate the transcription of the neurotrophin through a selfsustained loop.

The rat BDNF gene has a complex structure with four $5^{\prime}$ non-coding exons (I-IV) regulated by separate promoters, which are spliced to a common $3^{\prime}$ exon (V) encoding for neurotrophin protein (Timmusk et al, 1993). Recent evidence suggests that this system may be even more complex, because other $5^{\prime}$ exons have been identified in the rat gene, in accordance with the sequences described for the human and mouse genes (Liu et al, 2006). We show that the upregulation of exon V BDNF mRNA in frontal cortex after prolonged duloxetine administration is sustained mainly by 
a
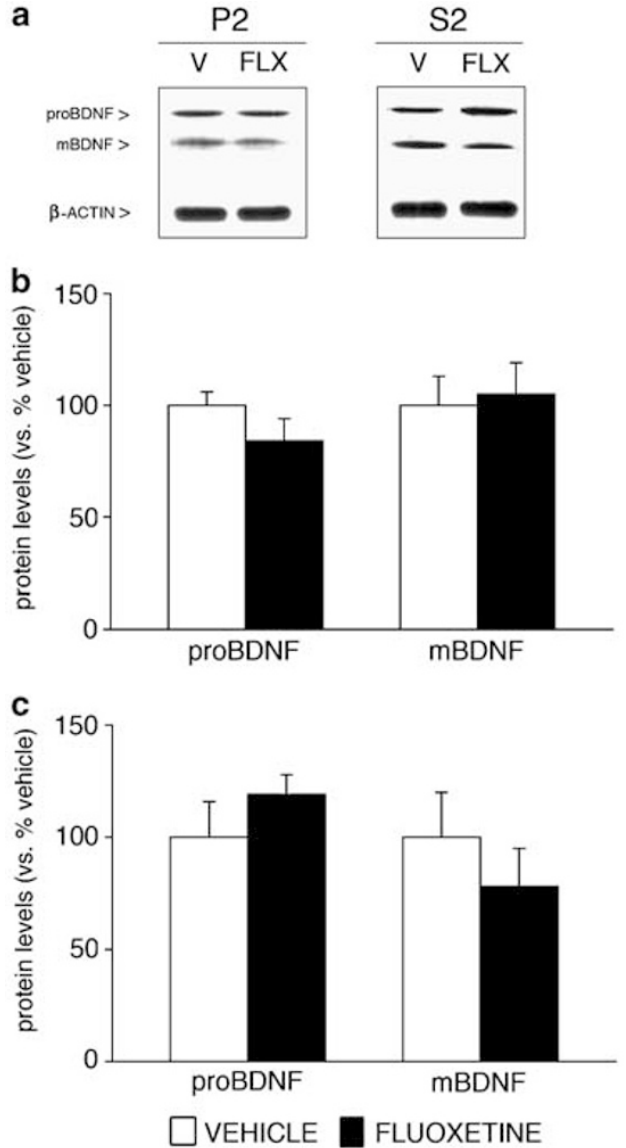

d
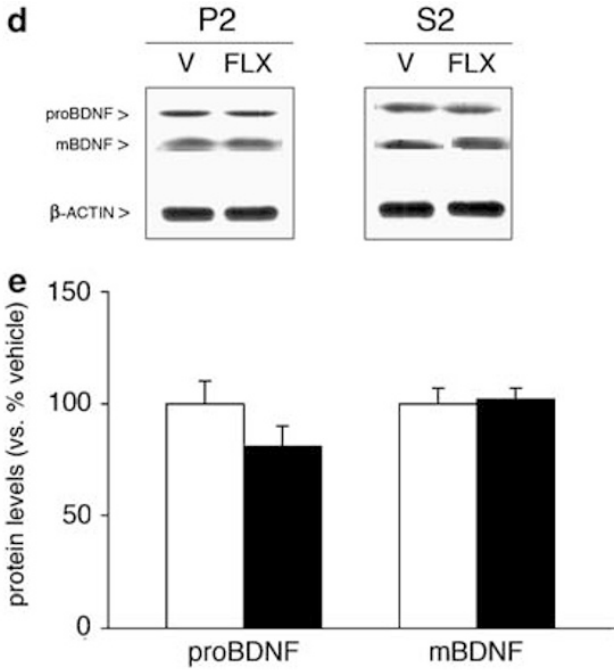

f

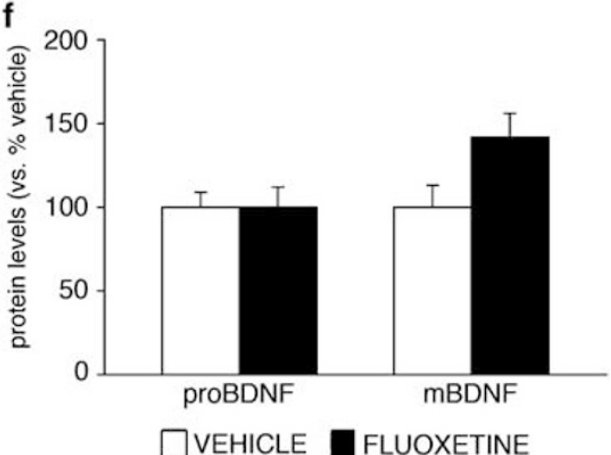

Figure 4 Effect of chronic treatment (2I days) with fluoxetine $(10 \mathrm{mg} / \mathrm{kg})$ on BDNF protein levels in rat frontal cortex and hippocampus. Western blot analysis of BDNF protein levels was carried out in $\mathrm{P} 2$ and $\mathrm{S} 2$ fractions of frontal cortex (a) and hippocampus (d) from rats chronically treated with vehicle ( $V$ ) or fluoxetine ( $F L X)$ and killed $24 \mathrm{~h}$ after the last drug administration. Arrows indicate the precursor (proBDNF) and the mature (mBDNF) forms of BDNF or $\beta$-actin, used as the internal standard. The quantitative data represent the levels of proBDNF and mBDNF in crude synaptosomal and cytosolic fractions of frontal cortex ( $b$ and $c$, respectively) or hippocampus (e and f, respectively) and are expressed as a percentage of control values (animals treated with vehicle, set at 100\%). Bar graphs show means \pm SEM from six to eight independent determinations.

the transcription of exons I, IIc, and III, whose mRNA levels are significantly increased only after repeated administration. Such effect is evident in the animals killed $1 \mathrm{~h}$ after the last administration, in good agreement with the analysis of the common exon $\mathrm{V}$, whereas $24 \mathrm{~h}$ later a small increase was evident only for exon I. The discrepancy observed at the latter time point may be related to the use of different techniques for mRNA analysis, although the possibility exists that the newly described $5^{\prime}$ exons (Liu et al, 2006), not investigated in the present work, might be modulated under the same experimental conditions. As a more consistent upregulation of different BDNF exons has been observed following prolonged treatment with noradrenaline reuptake blockers or MAO inhibitors rather than SSRIs (Dias et al, 2003), it may be inferred that the blocking properties on noradrenaline reuptake might exert a relevant contribution to the effects of duloxetine on $5^{\prime}$ BDNF exons (Dias et al, 2003; Dwivedi et al, 2006). The biological significance of the different transcripts remains unknown, although promoters I and III, whose expression is increased by chronic duloxetine, are most sensitive to activity-dependent regulation (Timmusk et al, 1993; Tabuchi et al, 2002; Chen et al, 2003; Rattiner et al, 2004). Tsankova et al have recently shown that the mRNA levels for BDNF exon III were significantly reduced in an animal model of depression, an effect that was normalized by chronic imipramine treatment. Because stress represents a precipitating event in psychiatric diseases, these data suggest a putative etiological role at least for one of the $5^{\prime}$ exons positively modulated by duloxetine administration (Tsankova et al, 2006).

One interesting and novel aspect of our study concerns the modulation of BDNF protein following chronic duloxetine treatment. When compared with transcriptional changes, more limited information on antidepressantrelated regulation of $\mathrm{BDNF}$ protein is present in the literature. With the exception of ECT, most antidepressant drugs have limited or no effect on BDNF protein levels (Altar et al, 2003; Jacobsen and Mork, 2004; Tardito et al, 2006). BDNF is present within the cell in two forms (Mowla et al, 2001) - the precursor and the mature - and can also be localized in different subcellular compartments, where its distribution may be influenced by genetic variants (Egan et al, 2003; Lessmann et al, 2003; Chen et al, 2004; Bramham and Messaoudi, 2005). We found that rats chronically treated with duloxetine have significantly higher levels of mBDNF in the crude synaptosomal fraction of the frontal cortex, with a concomitant reduction in the cytosolic fraction. We hypothesize that chronic duloxetine treatment 
produce not only a significant increase in BDNF protein but also its translocation from the cytosol to the 'synaptic' compartment. Because BDNF can be packaged into vesicles and secreted locally (Lessmann et al, 2003; Bramham and Messaoudi, 2005), chronic treatment with duloxetine might therefore increase this ready-to-use pool of neurotrophin that, at the local level, is critically involved in synaptic function and plasticity (Poo, 2001). Astroglial cells may also be present in the crude synaptosomal compartment (P2) and could contribute to the marked elevation of mBDNF after chronic duloxetine treatment. In fact, although astrocytes might not be able to newly synthesize BDNF, they can collect extracellular BDNF, which can be stored or even re-exocytosed (Rubio, 1997; Bramham and Messaoudi, 2005).

Because TrkB, the high-affinity receptor for BDNF, is required for antidepressant efficacy (Saarelainen et al, 2003), it is feasible to hypothesize that enhanced availability of the neurotrophin in the synaptosomal compartment may lead to augmented activation of TrkB. In line with this possibility, Wyneken et al recently reported that repeated antidepressant treatment enhances the levels of TrkB in a subcellular fraction that contain endocytic vescicles, which is suggestive of an increased internalization of the receptor upon ligand-induced activation (Wyneken et al, 2006). It is interesting to note that chronic fluoxetine does not alter the levels of BDNF protein in any cellular compartment. Although it is not possible to make a general statement on different classes of antidepressants, our results provide support for differences between SNRIs and SSRIs in modulating BDNF processing and intracellular sorting following long-term exposure. Alternatively, the small changes produced by fluoxetine on neurotrophin mRNA levels under these experimental conditions (Molteni et al, 2006) might not be sufficient to produce significant changes at the protein level.

We do not know whether the changes observed in BDNF protein in the crude synaptosomal fraction are sustained by local synthesis of the neurotrophin or whether the protein is translocated from other cellular compartments (Bramham and Messaoudi, 2005; Lessmann et al, 2003). If reduced mBDNF in the cytosolic fraction after chronic duloxetine treatment may be suggestive of an increased translocation toward the synaptic compartment, the same does not hold true for proBDNF, which is decreased in the cytosol and unchanged in membranes, thus implying increased processing of the proBDNF in a selected cellular compartment. Because it is known that proBDNF can, upon release, activate p75 neurotrophin receptor and endanger cell viability (Lee et al, 2001; Lu, 2003), its reduced availability may therefore be beneficial for cell function and is in line with the possibility that long-term antidepressants may increase cellular resiliency.

Depression may be associated with decreased levels of the neurotrophin BDNF. Although defects in the BDNF gene may not necessarily yield a 'depressive' phenotype, the neurotrophin appears to be required for antidepressant activity (Saarelainen et al, 2003; Monteggia et al, 2004): the marked and specific increase of BDNF expression in cortical regions after duloxetine treatment may support antidepressant activity and, as previously mentioned, can lead to an improvement of structural and functional alterations observed in depressed subjects (Drevets et al, 1997; Rajkowska et al, 1999; Fossati et al, 2004).

In summary, our results, through the use of the novel antidepressant duloxetine, consolidate the idea that upregulation of the neurotrophin BDNF may represent a common event with antidepressant treatment, although the magnitude and anatomical profile of such modulation depend on the drug used (Duman and Monteggia, 2006; Nestler and Carlezon, 2006; Tardito et al, 2006). The regulation of BDNF expression by antidepressants appears to be a complex event, involving transcriptional changes that may also be determined by chromatin remodeling (Tsankova et al, 2006). We have now provided evidence for a novel degree of modulation, which refers to the possibility that antidepressant drugs may, in the long-term, enhance the synaptic pool of the neurotrophin and its putative role in the modulation of synaptic function.

\section{ACKNOWLEDGEMENTS}

This research has been supported in part by funding to MAR from the Italian Ministry of University and Research and the Ministry of Health and by an unrestricted grant from Eli Lilly Italia.

We thank Dr Michela Mioradelli for collaborating to part of this work.

\section{REFERENCES}

Altar CA, Whitehead RE, Chen R, Wortwein G, Madsen TM (2003). Effects of electroconvulsive seizures and antidepressant drugs on brain-derived neurotrophic factor protein in rat brain. Biol Psychiatry 54: 703-709.

Barbon A, Vallini I, La Via L, Marchina E, Barlati S (2003). Glutamate receptor RNA editing: a molecular analysis of GluR2, GluR5 and GluR6 in human brain tissues and in NT2 cells following in vitro neural differentiation. Brain Res Mol Brain Res 117: $168-178$.

Berton O, Nestler EJ (2006). New approaches to antidepressant drug discovery: beyond monoamines. Nat Rev Neurosci 7: 137-151.

Bramham CR, Messaoudi E (2005). BDNF function in adult synaptic plasticity: the synaptic consolidation hypothesis. Prog Neurobiol 76: 99-125.

Bymaster FP, Lee TC, Knadler MP, Detke MJ, Iyengar S (2005). The dual transporter inhibitor duloxetine: a review of its preclinical pharmacology, pharmacokinetic profile, and clinical results in depression. Cur Pharm Des 11: 1475-1493.

Castren E (2005). Is mood chemistry? Nat Rev Neurosci 6: 241-246.

Chen B, Dowlatshahi D, MacQueen GM, Wang JF, Young LT (2001). Increased hippocampal BDNF immunoreactivity in subjects treated with antidepressant medication. Biol Psychiatry 50: $260-265$.

Chen WG, West AE, Tao X, Corfas G, Szentirmay MN, Sawadogo M et al (2003). Upstream stimulatory factors are mediators of $\mathrm{Ca}^{2+}$ responsive transcription in neurons. J Neurosci 23: 2572-2581.

Chen ZY, Patel PD, sant G, Meng CX, teng KK, Hempstead BL et al (2004). Variant brain-derived neurotrophic factor (BDNF) (Met66) alters the intracellular trafficking and activity-dependent secretion of wild-type BDNF in neurosecretory cells and cortical neurons. J Neurosci 24: 4401-4411.

De Foubert G, Carney SL, Robinson CS, Destexhe EJ, Tomlinson R, Hicks CA et al (2004). Fluoxetine-induced change in rat expression of brain-derived neurotrophic factor varies depending on length of treatment. Neuroscience 128: 597-604. 
Dias BG, Banerjee SB, Duman RS, Vaidya VA (2003). Differential regulation of brain derived neurotrophic factor transcripts by antidepressant treatments in the adult rat brain. Neuropharmacology 45: 553-563.

Drevets WC, Price JL, Simpson Jr JR, Todd RD, Reich T, Vannier $\mathrm{M}$ et al (1997). Subgenual prefrontal cortex abnormalities in mood disorders. Nature 386: 824-827.

Duman RS, Monteggia LM (2006). A neurotrophic model for stress-related mood disorder. Biol Psychiatry 59: 1116-1127.

Dwivedi Y, Rizavi HS, Pandey GN (2006). Antidepressants reverse corticosterone-mediated decrease in brain-derived neurotrophic factor expression: differential regulation of specific exons by antidepressants and corticosterone. Neurosci 139: 1017-1029.

Egan MF, Kojima M, Callicott JH, Goldberg TE, Kolachana BS, Bertolino A et al (2003). The BDNF val66met polymorphism affects activity-dependent secretion of BDNF and human memory and hippocampal function. Cell 112: 257-269.

Fossati P, Radtchenko A, Boyer P (2004). Neuroplasticity: from MRI to depressive symptoms. Eur Neuropsychopharmacol Suppl 5: S503-S510.

Jacobsen JPR, Mork A (2004). The effect of escitalopram, desimipramine, electroconvulsive seizures and lithium on brain-derived neurotrophic factor mRNA and protein expression in the rat brain and the correlation to 5-HT and 5-HIAA levels. Brain Res 1024: 183-192.

Lee R, Kermani P, Teng KK, Hempstead BL (2001). Regulation of cell survival by secreted proneurotrophins. Science 294: 1945-1948.

Leonard BE (2001). Stress, norepinephrine and depression. J Psych Neurosci 26(Suppl): S11-S16.

Lessmann V, Gottmann K, Malcangio M (2003). Neurotrophin secretion: current facts and future prospects. Prog Neurobiol 69: 341-374.

Lindvall O, Bjorklund A, Divac I (1978). Organization of catecholamine neurons projecting to the frontal cortex in the rat. Brain Res 142: 1-24.

Liu Q-R, Lu L, Zhu X-G, Gong J-P, Shaham Y, Uhl GR (2006). Rodent BDNF genes, novel promoters, novel splice variants, and regulation by cocaine. Brain Res 1067: 1-12.

Lu B (2003). Pro-region of neurotrophin: role in synaptic modulation. Neuron 39: 735-738.

Molteni R, Calabrese F, Bedogni F, Tongiorgi E, Fumagalli F, Racagni G et al (2006). Chronic treatment with fluoxetine upregulates cellular BDNF mRNA expression in rat dopaminergic regions. Int J Neuropsychopharmacol 9: 307-317.

Monteggia LM, Barrot M, Powell CM, Berton O, Galanis V, Gemelli $\mathrm{T}$ et al (2004). Essential role of brain-derived neurotrophic factor in adult hippocampal function. Proc Natl Acad Sci USA 101: 10827-10832.

Mowla SJ, Farhadi HF, Pareek S, Atwal JK, Morris SJ, Seidah NG et al (2001). Biosynthesis and post-translational processing of the precursor to brain-derived neurotrophic factor. J Biol Chem 276: $12660-12666$.

Nagappan G, Lu B (2005). Activity-dependent modulation of the BDNF receptor TrkB mechanisms and implications. Trends Neurosci 28: 464-471.
Nestler EJ, Carlezon Jr WA (2006). The mesolimbic dopamine reward circuit in depression. Biol Psychiatry 59: 1151-1159.

Nibuya M, Morinobu S, Duman RS (1995). Regulation of BDNF and trkB mRNA in rat brain by chronic electroconvulsive seizure and antidepressant drug treatment. J Neurosci 15: 7539-7547.

Paxinos G, Watson C (1996). The Rat Brain in Stereotaxic Coordinates. Academic Press: New York.

Poo MM (2001). Neurotrophins as synaptic modulators. Nat Rev Neurosci 2: 24-32.

Rajkowska G, Miguel-Hidalgo JJ, Wei J, Dilley G, Pittman SD, Meltzer HY et al (1999). Morphometric evidence for neuronal and glial prefrontal cell pathology in major depression. Biol Psychiatry 45: 1085-1098.

Rattiner LM, Davis M, Ressler KJ (2004). Differential regulation of brain-derived neurotrophic factor transcripts during the consolidation of fear learning. Learn Mem 11: 727-731.

Riva MA, Molteni R, Lovati E, Fumagalli F, Rusnati M, Racagni G (1996). Cyclic AMP-dependent regulation of fibroblast growth factor-2 messenger RNA levels in rat cortical astrocytes: comparison with fibroblast growth factor-1 and ciliary neurotrophic factor. Mol Pharmacol 49: 699-706.

Rubio N (1997). Mouse astrocytes store and deliver brain-derived neurotrophic factor using the non-catalytic gp95TrkB receptor. Eur J Neurosci 9: 1847-1853.

Saarelainen T, Hendolin P, Lucas G, Koponen E, Sairanen M, MacDonald E et al (2003). Activation of the TrkB neurotrophin receptor is induced by antidepressant drugs and is required for antidepressant-induced behavioral effects. J Neurosci 23: 349-357.

Santarelli L, Saxe M, Gross C, Surget A, Battaglia F, Dulawa S et al (2003). Requirement of hippocampal neurogenesis for the behavioural effects of antidepressants. Science 301: 805-809.

Tabuchi A, Sakaya H, Kisukeda T, Fushiki H, Tsuda M (2002). Involved of an upstream stimulatory factor as well cAMPresponsive element-binding protein in the activation of brainderived neurotrophic factor gene promoter I. J Neurosci 277: 35920-35931.

Tardito D, Perez J, Tiraboschi E, Musazzi L, Racagni G, Popoli M (2006). Signaling pathways regulating gene expression, neuroplasticity, and neurotrophic mechanisms in the action of antidepressants: a critical overview. Pharmacol Rev 58: 115-134.

Timmusk T, Palm K, Mesis M, Reintam T, Paalme V, Saarma M et al (1993). Multiple promoters direct tissue-specific expression of the rat BDNF gene. Neuron 10: 475-489.

Tsankova NM, Berton O, Renthal W, Kumar A, Neve RL, Nestler EJ (2006). Sustained hippocampal chromatin regulation in a mouse model of depression and antidepressant action. Nat Neurosci 9: 519-525.

Wyneken U, Sandoval S, Jorquera F, Gonzalez I, Vargas F, Falcon R et al (2006). Clinical relevant doses of fluoxetine and reboxetine induce changes in the $\operatorname{TrkB}$ content of central excitatory synapses. Neuropsychopharmacology 31: 2415-2423. 